\title{
Chk1 Inhibitor GDC-0575
}

National Cancer Institute

\section{Source}

National Cancer Institute. Chk1 Inhibitor GDC-0575. NCI Thesaurus. Code C116845.

A small molecule inhibitor of cell cycle checkpoint kinase 1 (Chk1), with potential chemosensitization activity. Chk1 inhibitor GDC-0575 specifically binds to and inhibits Chk1; this may result in tumor cells bypassing Chk1-dependent cell cycle arrest in the S and G2/M phases, which permits the cells to undergo DNA repair prior to entry into mitosis. Therefore, Chk1 inhibition may sensitize tumor cells to the DNA-damaging effects of certain chemotherapeutic agents. Chk1 is an ATP-dependent serine-threonine kinase that phosphorylates cdc25 phosphatases in response to DNA damage. This results in both inhibitory tyrosine phosphorylation of cyclin-dependent kinase (CDK)-cyclin complexes and cell cycle arrest, which facilitates DNA damage repair. 